\title{
DE DE GRUYTER OPEN \\ SUPPLY CHAIN MANAGEMENT AND CUSTOMER SATISFACTION IN SMALL TO MEDIUM ENTERPRISES
}

\author{
Osayuwamen Omoruyi* \\ Vaal University of Technology, South Africa

\section{Chengedzai Mafini} \\ Vaal University of Technology, South Africa
}

\begin{abstract}
To circumvent the possibility of business failure, small to medium enterprises in emerging economies face mounting pressure to increase the satisfaction of their customers. The adoption of supply chain management practices is critical to the provision of quality products and services as well as the satisfaction of customers by small to medium enterprises. This paper investigated the relationship between customer satisfaction, supply chain management practices and three input factors; namely, product quality, flexibility and product variety in small to medium enterprises. The study adopted a quantitative approach in which a four section questionnaire was distributed to 131 managers in small to medium enterprises based in Gauteng Province, South Africa. Hypotheses were tested using regression analysis. The results of the study revealed that product quality and flexibility predicted supply chain management practices. Supply chain management practices were also statistically significant, and mediated the relationship between customer satisfaction and product quality and flexibility. Based on these results, conclusions were drawn and appropriate recommendations were made.
\end{abstract}

JEL Classification: L1

Keywords: Product quality, flexibility, product variety, supply chain management practices, customer satisfaction

\section{Introduction}

That small and medium enterprises (SMEs) are renowned drivers of economic growth in emerging economies such as South Africa is a long-established fact. SMEs are well known for their contributions to the development and survival as well as revenue generators to any economy (Rosenbusch, Brinckmann and Bausch, 2011). Even so, government, institutions, practitioners, as well as researchers have extensively commended and acknowledged the importance of SMEs as contributors to economic growth in terms of poverty alleviation (Sui, Lin, Fang and Lui, 2006),

\footnotetext{
* Corresponding author, Address: Department of Logistics, Faculty of Management Sciences, Vaal University of Technology P. Bag X021 Vanderbijlpark, 1900. South Africa., Tel: +27169509520 Email: osayuiwameno@vut.ac.za
} 
reduced unemployment through job creation (Bhutta, Rana and Asad, 2008), and innovators of new product and services as well as technological advancement (Shin and Lee, 2013). However, it has been observed that the survival and the continued existence of SMEs strongly depends on their ability to fully integrate supply chain management (SCM) practices in a strategic manner in order to provide quality products and services, and to provide product varieties that satisfy the dynamic needs of modern-day customers (Kim, Cavusgil and Cavusgil, 2013; Sharifl et al., 2013).

Customer satisfaction is the key to SME business growth and continued existence (Chow, 2014; Sun and Kim, 2013). It has been identified as the key indicator that differentiates between high or successful business performance and a low or unsuccessful business performance within the business environment in present-day South Africa (Sharifl et al., 2013). In other words, when a customer is satisfied, there is a strong possibility that the customer might become loyal, which results in the improvement of organisational performance (Terpstra and Verbeeten, 2014). A chain of customers is established through word of mouth as a result of customer satisfaction derived from the product or service supplied by a particular organisation (Subramanian et al., 2014). SMEs in South Africa therefore face the challenge of adopting appropriate strategies necessary to satisfy their demanding customers.

The aim of this paper is to examine the relationship between customer satisfaction, SCM practices and three input factors, namely product quality, product variety and flexibility among SMEs in South Africa. There are several perspectives that attempt to address the issue of best practice in terms of customer satisfaction strategies. Noteworthy ones include inter alia; the SWOT analysis (Horn and Pesonen, 2014), Resource-Based View (RBV) (Nath, Nachiappan and Ramanathan, 2010; Wong and Karia, 2010), Outsourcing (Mukherjee Gaur and Datta, 2013; Schwarz, 2014), Materials Management (Lindahl, Robert, Ny and Broman, 2014) and Total Quality Management (TQM) (Agus and Hassan, 2011; Todorut, 2012; Bon and Mustafa, 2013). A notable aspect though, is that none of these strategies addresses the relationship between strategic SCM practices and product quality, product variety and flexibility as business strategies that could enhance customer satisfaction. Besides, the current study is based on the South Africa context rather than Europe, USA or Asia, which provides an element of novelty and fresh perspectives from a hitherto overlooked geo-spatial context. The study is significant in that it adds new literature to the existing body of business management literature on supply chain strategy, quality, variety and flexibility among SMEs. Also, the results of the study have practical implications for SME owners/managers and managers of larger organisations as well as shareholders within the business environment in terms of customer satisfaction through the adoption of SCM practices.

\section{Literature Review}

\section{Product Quality}

For the purposes of this study, the concept of service quality in the supply chain is defined as the overall consumer impression/perception of the products and services provided within that supply chain (Prakash, 2011). In order for an SME to compete effectively and to gain a sustainable advantage over its competitors, it is necessary to improve the quality of its products and services (Sohal, Netto, Fitzpatrick and 
Noori, 2001). Product and service quality is a powerful tool to improve an SME's performance and growth. Mentzer, Flint and Hult (2001) advocate that since the quality of products offered within a supply chain has a significant impact on revenue and profitability, it is important to adopt any strategy that leads to improvements in product quality. As a result, SMEs are redesigning their business strategy to incorporate a SCM strategy to achieve a high level of customer satisfaction through product and service quality (Coyle, Bradi and Langley, 2003). On the one hand, a study conducted by Saura, Frances, Contri and Blasco (2008) found out that the two major effects of high quality SCM products and services are satisfaction and loyalty within customers. On the other end, poor SCM product and service quality may lead to the lack of access to innovation and expertise, which may result in customers switching over to substitute products (Ballou, 2004; Louw and Venter, 2006). Based on the aforementioned aspects, it is logical to envisage a positive relationship between the quality of products and services and the adoption of SCM practices within an SME supply chain. This leads to the following hypotheses:

$\mathrm{Ho}_{1}$ : There is no relationship between the quality of products and services and the adoption of SCM practices in SMEs.

$\mathrm{Ha}_{1}$ : The higher the quality of products and services, the easier the adoption of SCM practices in SMEs.

\section{Flexibility}

Flexibility may be perceived as an attribute of a system's technology or the SMEs ability to cope with uncertainty, and to adapt or respond to changes (Tachizawa and Gimenez, 2010). According to Choy et al. (2008), increasing flexibility in the supply chain can be regarded as a strategy for improving the system's responsiveness to change. Flexibility is also required to face increasing variety in its environmental needs and expectations without incurring excessive costs, time, organisational disruptions and performance losses (Zhang, Vonderembse and Su Lim, 2003; Narasimhan, Talluri and Das, 2004; Sanchez and Perez, 2005). Basic supply chain flexibility occurs with regard to machines, material handling, operations, automation, labour process, routing, product design, delivery, volume, expansion, programming, production and market flexibility (Duclos Vokurka and Lummus, 2003, Gong 2008). Quick responses to customer orders are the reason for the implementation of a SCM strategy in the increasingly competitive environment (Ahmed, Hardaker and Carpenter, 1996). As a result, SMEs are seeking to enhance flexibility in the business strategy (Zhang et al., 2003, Choy et al., 2008).

Flexibility produces a different way of thinking in order to serve each distinct customer's needs and for meeting time-based constraints (Duclos et al., 2003). Besides being a powerful tool in a system that enhances value offerings appreciated by customers, flexibility ensures stable performance under changing conditions (Lingyee and Ogunmokun, 2008). Increased flexibility in supply chain systems can be regarded as a strategy for improving the responsiveness of SMEs particularly in the decision making process (Sanchez and Perez, 2005). Thus flexibility enables SMEs to make alternative decisions. This leads to the following hypotheses:

$\mathrm{Ho}_{2}$ : There is no relationship between flexibility within an SME and the adoption of SCM practices

$\mathrm{Ha}_{2}$ : The greater the flexibility within an SME supply chain strategy, the easier it is to adopt SCM practices 


\section{Product Variety}

The ever-increasing competitive environment today requires low-cost, highquality products, and increasing varieties of goods and services that differentiates these products and services from alternative substitutes. (Duclos et al., 2003). According to Mostert, Oosthuizen and Smith (2007), product substitutes are those products or services that consumers can turn to because they satisfy the same need. When customers find little or no difference between an organisation's product and those of a competing supplier, then the product is highly substitutable. In other words, the customer is readily willing to take a second-choice brand when the first product is not immediately available (Ballou, 2004).

SMEs strategically determine competitors' substitute products to differentiate their products in order to gain competitive advantages and to reach their set goals (Molz, 1998). Additionally, SMEs use SCM skills to convince customers that their products are different from those of the competitors through distribution capabilities that provide product availability at a high level so that customers will not have to consider a substitute product (Muradzikwa, Smith and De Villiers, 2004). Higher substitutability usually means a greater chance for a customer to select a competing product, possibly resulting in lost sales for SMEs (Venter, 2006). Nevertheless, with the use of SCM strategies, lost sales can be eliminated through transportation choices and storage choices (Ballou, 2004). Based on these assertions, the following hypotheses are proposed;

$\mathrm{Ho}_{3}$ : There is no relationship between product variety and the adoption of SCM practices in SMEs

$\mathrm{Ha}_{3}$ The greater the variety of products offered by an SME, the greater the need to adopt SCM practices

\section{Customer Satisfaction}

Customer satisfaction is the art of making the customer happy by listening to them and responding to their needs (Zhang et al., 2003). Customer satisfaction involves managing the business with the prime intention of satisfying customer needs rather than the needs of management (Herrmann, Huber and Braunstein, 2000). It is delivering to customers more than they request and consistently exceeding their expectations (Matzler and Hinterhuber, 1998). Customer satisfaction achieves for SMEs an increased level of customer loyalty, an increase in cash flow and a decrease in operating costs (Gosling, Shang and Marlow, 2005). As a result, customers will be willing to pay more for high quality products and services (Venter, 2006). Effective strategic supply chain decisions have a profound impact on competitive position, profitability, market share, as well as impact on the specific needs of the consumer (Song, Dong and $\mathrm{Xu}, 2014$ ). Examples of these needs are consumer trends, type of products, services, quantities, qualities and time (Hugo, Babenhorst-weiss and Van Rooyen, 2002). As observed by Saura et al. (2008), SCM is the connection between production and consumption, a cost-reduction technique and a product differentiation strategy that brings greater customer satisfaction. Furthermore, SMEs tend to view themselves as entities that must improve on their supply chain service quality in order to compete effectively, enhance customer satisfaction and improve overall business performance (Millen, Sohal and Moss, 1999). This leads to the following hypotheses: 
$\mathrm{Ho}_{4}$ : There is no relationship between the adoption of SCM practices and customer satisfaction in SMEs

Ha4: Adoption of SCM practices leads to higher the customer satisfaction amongst SMEs

\section{Conceptual Framework}

The conceptual framework shown in Figure 1 was developed based on the literature review. The conceptual framework illustrates the proposed linkage between product quality, flexibility and product variety, which are taken to be the antecedents of SCM practices. In turn, the adoption of SCM practices is taken to be a driver of customer satisfaction.

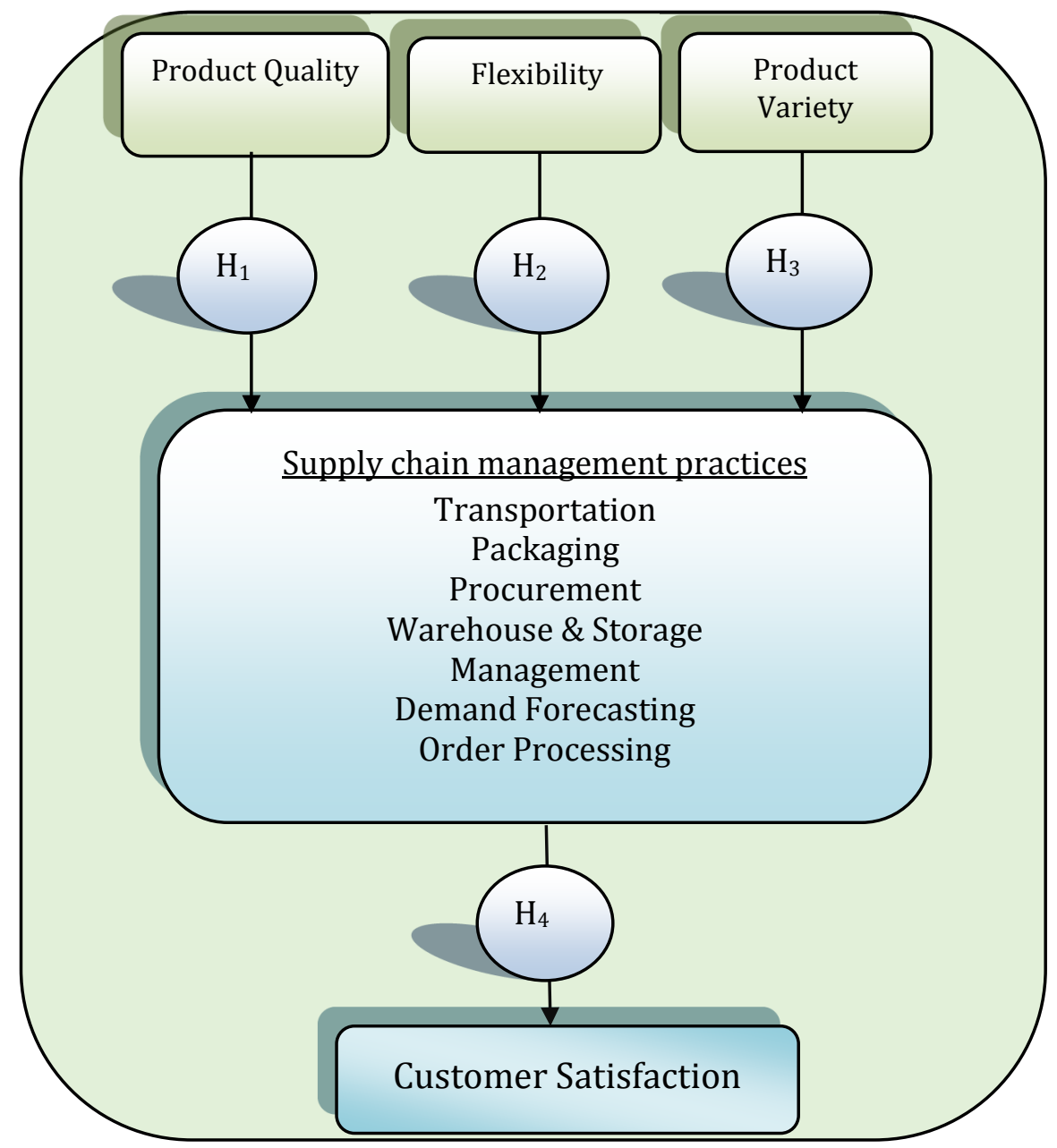

Figure 1. Conceptual Framework: Product Attributes, Supply Chain Management Practices and Customer Satisfaction 


\section{Research Methodology}

\section{Research Design}

A quantitative approach using the cross-sectional descriptive survey technique was used (Creswell, 2013). The quantitative nature of the study was grounded on the need to quantify the data collected and to generalise the findings (Fouche, 2005). The quantitative approach was selected for the current study because quantitative research enhances the objectivity of the study since it is cheap, flexible and less time-consuming to conduct.

\section{Sampling Design}

The target population for the current study consisted of owners or managers of SMEs located in a selected local municipality which is based in Gauteng Province, South Africa. Respondents were selected using the probability random sampling technique. Using the historical approach, the sample size was set at $n=200$, consistently with previous studies (Ahola et al., 2008; Dolgui and Prodhon, 2007; Mula et al., 2006; Wong, Lai and Ngai, 2009) in which almost the same ranges of sample size were used to examine the benefits of logistics strategies in SMES.

An analysis of the demographic characteristics of the respondents showed that approximately $61 \%(n=80)$ of the respondents were male and $39 \%(n=51)$ were female. In addition, a majority of the business owners/ managers $(64 \% ; n=84)$ were aged above 30 years and the remaining $36 \%(n=47)$ were aged below 30 years. In terms of academic qualifications, $43 \%(n=56)$ of respondents were in possession of either a higher education diploma or a certificate; $14 \%(n=18)$ were in possession of at least a university degree and $35 \%(n=46)$ had completed matric. The later characteristic was favourable to the current study because it indicated that the literacy levels of respondents were sufficiently high, which was a reflection of their ability to understand the questions in the data collection instrument.

\section{Research Instrument}

Data were collected using a four section questionnaire. Section A of the questionnaire elicited information on the demographic characteristics of the respondents as well as the profile of the SMEs. Section B elicited data on SCM practices implemented by the SMEs. Questions used in Section B were adapted from previous studies (Horvath, Autry and Wilcox, 2005; Voortman, 2004). Questions in Section C (adapted from Hong, 2007; Watson, Goodhue and Wixom, 2001) focused on product quality, flexibility and product variety. Section D elicited questions (adapted from Caridi and Cavalieri, 2004; Ramond and Croom, 2008) on customer satisfaction from the perspectives of owners and managers of SMEs. The adaptation involved essential adjustments to the language used, grammar, the level of difficulty in each question and the reduction in the number of items used. Moreover, only those questions that were relevant to the constructs examined in this study were used. Questions on Sections B, C and D were configured in a six point Likert style format anchored by ' 1 ' = not important and ' 6 ' = the very important.

In order to ascertain content validity, which is the representativeness of the content of the measurement instrument, the questionnaire was pre-tested with a conveniently selected sample of 15 SMEs. Feedback from the pre-test sample was used as the basis for effecting some changes to the questionnaire. After the pre- 
test, the refined questionnaires were re-distributed to a different conveniently selected sample of 20 SMEs as a pilot study in order to check the reliability of the scale. The pilot study revealed that the scale had satisfactory reliability levels which ranged from 0.716 to 0.864 and that there were no further ambiguities in the questions.

In the collection of data, a number of ethical considerations inter alia; the right of respondents to confidentiality, anonymity, privacy, protection as well as informed consent were observed. Eventually, out of the 200 questionnaires that were initially administered to SMEs, 147 were returned, giving a return rate of $74 \%$. However, 16 questionnaires were eliminated in the screening process, culminating in 131 questionnaires, which were used in the actual data analysis.

\section{Data Analysis}

In the present study, data analyses were conducted using the Statistical Package of the Social Sciences (SPSS version 22.0). Descriptive statistics were used to analyse the demographic characteristics of the sample and the hypothesised framework was tested using regression analysis.

\section{Research Results}

\section{Reliability and Validity of the Measurement Scale}

Reliability was measured using Cronbach Alpha Coefficient. The Cronbach alpha values for the subscales ranged between 0.716 and 0.864 , whilst the Cronbach alpha value for the entire scale was 0.829 . These results validate the proficiency of the measurement scale in capturing the constructs investigated in this study. The internal consistencies (reliability) of these measurement scales are reported in Table 1.

Table 1. Reliability values for the sub scales

\begin{tabular}{|l|c|c|c|}
\hline Factor & N & No of Items & Cronbach Alpha \\
\hline Product quality & 131 & 5 & 0.716 \\
\hline Flexibility & 131 & 4 & 0.803 \\
\hline Product variety & 131 & 6 & 0.725 \\
\hline SCM practices & 131 & 7 & 0.864 \\
\hline Customer satisfaction & 131 & 6 & 0.773 \\
\hline \multicolumn{2}{|l}{ Overall Cronbach Alpha for the entire Scale = } \\
\hline
\end{tabular}

Content and face validity of the instrument were ascertained through pretesting the questionnaire with a conveniently selected sample of 30 SMEs. Moreover, a panel consisting of three academics who are experts in the fields of entrepreneurship and supply chain management reviewed the questionnaire to 
ascertain its validity. Based on the feedback from the pre-test and academic reviews, several minor revisions were made to the questionnaire with a view to enrich its validity in addressing the aim of the study. Predictive validity was measured through regression analysis. Causality was explained by four of the three of the four factors in their relationship with customer satisfaction.

\section{Regression Analysis: Product Quality, Flexibility, Product Variety and Supply Chain Management Practices}

In this study, regression analysis using the enter method was utilised to test the proposed hypotheses. According to Malhotra (2010), regression analysis is an inferential statistical procedure for identifying the variables that either predict or provide the best clarification for the part of the total variance within the scores of the dependent constructs. One of the main assumptions made to support the use of regression analysis in this study is the presence of linearity between the independent and dependent constructs. In the two regression models resulting from the analyses, the values of the Variance Inflation Factor (VIF) fell within the maximum allowable threshold of 10 prescribed by Field (2009). Also, tolerance values were satisfactory because they were above the minimum of 0.5 recommended by Denis (2011). This implies that multicollinearity diagnosis did not indicate any severe threat, which rendered a regression analysis both practicable and suitable. With this assumption satisfied, product quality, flexibility and product variety were entered into the regression model as independent variables (constructs) while SCM practices was entered into the regression model as the dependent variable. These results are reported in Table 2.

Table 2. Regression Model 1- product quality, flexibility, product variety and supply chain management practices

\begin{tabular}{|c|c|c|c|c|c|}
\hline \multirow{3}{*}{$\begin{array}{l}\text { Independent } \\
\text { variables: Product } \\
\text { quality, flexibility \& } \\
\text { Product variety }\end{array}$} & \multicolumn{5}{|c|}{ Dependent variable: SCM practices } \\
\hline & \multirow{2}{*}{$\begin{array}{l}\text { Standardised } \\
\text { Coefficients } \\
\text { Beta }\end{array}$} & \multirow[t]{2}{*}{$\mathbf{T}$} & \multirow[t]{2}{*}{ Sig. } & \multicolumn{2}{|c|}{$\begin{array}{c}\text { Collinearity } \\
\text { Statistics }\end{array}$} \\
\hline & & & & Tol & VIF \\
\hline Product quality & 0.372 & 4.240 & 0.000 & 0.567 & 1.874 \\
\hline Flexibility & 0.265 & 5.825 & 0.001 & 0.624 & 1.883 \\
\hline Product variety & -0.101 & 1.959 & 0.504 & 0.543 & 2.423 \\
\hline \multicolumn{6}{|c|}{$\begin{array}{l}\text { Model summary: } \\
R=0.479 ; \quad \text { Adjusted } R^{2}=0.451 ; F=12.763 ; \text { Std. error of the estimate }=0.7335 ; \\
\text { Tol= Tolerance VIF= Variance Inflation factor }\end{array}$} \\
\hline
\end{tabular}

Product quality, flexibility and product variety accounted for approximately $45 \%\left(R^{2}=0.451\right)$ of the variance explained in SCM practices. This implies that about $55 \%$ of the variance in SCM practices is explained by other extraneous factors which were not examined in this study. 


\section{Regression Analysis: Supply Chain Management Practices and Customer Satisfaction}

A second linear regression procedure was applied to assess the possible existence of a predictive relationship between SCM practices (independent variable) and customer satisfaction (dependant variable). The results are reported in Table 3.

Table 3. Regression Model 2- Supply chain management practices and customer satisfaction

\begin{tabular}{|c|c|c|c|c|c|}
\hline \multirow{3}{*}{$\begin{array}{l}\text { Independent } \\
\text { variable: } \\
\text { SCM practices }\end{array}$} & \multicolumn{5}{|c|}{ Dependent variable: Customer Satisfaction } \\
\hline & \multirow{2}{*}{$\begin{array}{c}\begin{array}{c}\text { Standardised } \\
\text { Coefficients }\end{array} \\
\text { Beta }\end{array}$} & \multirow[t]{2}{*}{$\mathbf{T}$} & \multirow[t]{2}{*}{ Sig } & \multicolumn{2}{|c|}{$\begin{array}{c}\text { Collinearity } \\
\text { Statistics }\end{array}$} \\
\hline & & & & Tol & VIF \\
\hline SCM practices & 0.365 & 6.132 & 0.001 & 0.724 & 1.679 \\
\hline
\end{tabular}

Regression Model 2 showed an $\mathrm{R}^{2}$ value of 0.391 , which depicts that approximately $39 \%$ of the variation of the customer satisfaction among SMEs can be explained by SCM practices. As such, approximately $61 \%$ of the variation in customer satisfaction is explained by other extraneous factors which remain unaccounted for in the present study.

\section{Discussion}

Alternative hypothesis $\mathrm{Ha}_{1}$ was supported and was therefore accepted because the product quality factor emerged as statistically significant $(\beta=0.372$; $t=4.240 ; p<0.000$ ) in the regression in the regression analysis. This result demonstrates that product quality is a predictor of the ease of adoption of SCM practices by SMEs. As mentioned by Ellegaard (2006) SMEs must position themselves strategically to be more competitive, to meet domestic, international and globalisation challenges and to offer good product/service design and performance (quality) (Genchev, 2009). This may be achieved by using SCM practices that play a key role in aligning business strategy such as delivery, ordering, productivity, responsiveness to customer needs (Langford, 2007). SMEs originate from individuals, who identify new opportunities in society and who are motivated to exploit such opportunities (March and Hevner, 2007). In other words, even if a product is produced in the right time, and is available at the right price, it will be useless if it is not of a satisfactory quality that meets the needs of the customer (Waller, 2003). SMEs, be they strategic, less strategic or somewhat strategic regard the quality of their products and services as necessary ingredients improve the overall business performance, and to increase sales (Park, 2006). Some studies (Saura et al., 2008; Wixom and Watson, 2001) point out that considering how to improve SCM practices without considering the impact of 
product and service quality would be to omit from the theoretical framework one of the most important tools for controlling consistency, improving efficiency, and improving supply chain operations. Therefore, for an SME to compete effectively and to gain sustainable advantages over its competitors it is necessary to improve the quality of its products and services (Sohal, Netto, Fitzpatrick and Noori, 2001).

Alternative Hypotheses $\mathrm{Ha}_{2}$ found support and was accepted in the present study because the regression model showed that the flexibility factor was statistically significant $(\beta=0.265 ; t=5.825 ; p<0.001)$. This result denotes that the ease of adoption of SCM practices within an SME is predicted by the degree of flexibility within that SMEs supply chain strategy. According to Autry (2005) the strategic approach to SCM is built on a strong and flexible foundation. In addition, Chen (1999) suggests that flexibility in supply chains may well represent potential sources of improved efficiency. The findings of a study by Zhang et al. (2003) further show that flexibility enables SMEs to introduce new products quickly, support rapid product customisation, and shorten manufacturing lead times. As suggested by Lai, Ngai and Cheng (2002), elements such as on-time delivery of products and innovation capabilities among larger organisations, greater reliance on supply-chain relationships, shifting channel power and the globalisation of competition found in recent competitive environment, all point to greater opportunities to use flexibility to enhance competitiveness. After all, supply chain flexibility focuses on filling customer orders, rather than on improving efficiency and effectiveness of equipment to increase responsiveness and create a level of performance that enables firms to build competitive advantage over competitive rivals through customer satisfaction and loyalty (Molz, 1998), Moreover, SMEs have realised that to provide a quick response to changing customer needs, to cope successfully with uncertainty, to minimise inventory cost and to achieve high levels of customer satisfaction is to display the flexibility necessary for success (Skintzi, loannou and Prastacos, 2008). It can be suggested then that SMEs must set their goals based on proper prior attention to both the organisational flexibility and technical flexibility contexts, which are critical ingredients for success in supply chains.

In the current study, Alternative Hypothesis $\mathrm{Ha}_{3}$ did not find support and was therefore rejected because the results of the regression analysis showed that product quality was statistically insignificant $(\beta=-0.101 ; t=1.959 ; p<0.504)$. This result signifies that product variety does not necessarily predict the ease of adoption of SCM strategies within SMEs. These results are consistent with the findings by Van der vorst, Beulens and Van beek (2005), Sanchez and Perez (2005), who found no association between product and service variety and adoption of SCM practices. However, the results of the current study contradict the findings of studies conducted by Gong (2008) and Gosling, Purvis and Naim (2009) which concluded that it is easier to adopt SCM practices when there is greater product variety within a supply chain. The results of the current study could be attributed to the fact that SMEs are smaller entities which may struggle to maintain and sustain more complex systems and operations, such as when their product mix is highly variable. As revealed by Sui et al. (2006), some smaller companies have either become bankrupt or liquidated because they diversified prematurely into areas that they are unprepared to service satisfactorily. Other smaller organisations 
were unsuccessful because they introduced products without conducting adequate market research (Bowersox, Closs and Cooper, 2002). This is because smaller companies may not have the capacity in terms of resources such as expertise, finances experience and technology necessary to sustain their adopted operational models, which may be more complex than they realized (Ellegaard, 2008). In view of this, some scholars (Coyle, Bardi and Langley, 2003; Tassabehji and Moorhouse, 2008) suggest that a focus strategy could be a better option for small start-up operations because they compel the company to concentrate on a specific product or market niche, which is less susceptible to unpredictable market, price and cost swings. It is logical then to suggest then that unless such factors are taken into consideration, product variety may not necessarily stimulate easier adoption of in SCM practices within SMEs.

Alternative Hypothesis $\mathbf{H}_{\mathbf{4}}$ was supported in this study because the regression model showed a statistically significant relationship $(\beta=0.365 ; t=$ 6.132; $p<0.001$ ) between SCM practices and customer service. This result depicts that the degree of customer satisfaction within an SME can be indexed on the extent to which SCM practices have been embraced and implemented by the concerned SME. It is also logical for one use the adoption of SCM practices to forecast the future levels of customer satisfaction in an SME. These findings are grounded in the results of a previous study by Paulraj, Chen and Flynn (2006) which found that supply chain strategies such as outsourcing, strategic alliance, implementation of information technology and Just in Time (JIT) may lead to the enhanced quality of products and services as well as increased flexibility and responsiveness to the requirements of customers/clients. Genchev (2009) also found that the adoption of supply chain strategies may result in lower inventory levels, reduced risk, decreases in total costs, superior firm financial performance and better competitive advantages. Taylor (2008) adds that improved order management, streamlined operational efficiency, decreasing inventory levels and the increased ability to reduce delivery lead times are principal prerequisites to gaining competitive advantages in SMEs. Still, skills upgrading through the training of workers, acquisition of supply sources, increasing operational capacity, creating strategic alliances and the use of outsourcing strategies are critical in generating high customer satisfaction (Ballou, 2004). Duclos et al. (2003) further opine that customer satisfaction is the key focus of any supply chain strategy and is influenced by a constellation of practices that include outbound transportation, packaging, procurement, demand forecasting, order processing, warehousing and reverse logistics, among others. Therefore, it is paramount that all SCM practices be expedited and optimised in order for SMEs to improve the levels of satisfaction amongst their customers.

\section{Limitations and Implications for Further Research}

The study is limited in that it focused on the adoption of SCM practices in Gauteng province only, and does not fully represent all the SMEs in South Africa. Consequently the results of the study cannot be generalised to all SMEs. Additionally, the shortcomings associated with quantitative methodologies used in the current study are acknowledged. 
The study has several implications for further research. Any investigation into interventions should be aimed at empowering SMEs to implement SCM practices that include the obtaining of supply sources which generates collaborative relationships with particular suppliers so as to achieve long-term commitment and goals. Supplier relationships can also enrich strategic alliances based on reciprocal trust and enable SMEs to increase automation and improve supply chain information technology. Educational interventions on supply chain strategies could be tested through a longitudinal study to explore improvements amongst SMEs that are implementing SCM practices. The scope of further research should be broadened to include SMEs in the entire South African context, in order to provide a better picture of the extent of implementation, challenges as well as benefits of utilising SCM practices in SMEs in the country. Both qualitative and quantitative methods of data collection are recommended for any further research on logistics in SMEs.

\section{Conclusion and Recommendations}

The purpose of this study was to investigate the relationship between customer satisfaction, SCM practices and quality, variety and flexibility amongst SMEs in South Africa. Two input factors; namely, product quality and flexibility emerged as significant predictors of the ease of adoption of SCM practices in SMEs. However, product variety had no significant relationship with the adoption of SCM practices. In addition, SCM practices significantly predicted customer satisfaction. It can be concluded then that there is a positive and significant relationship between customer satisfaction and two factors; specifically, product quality and flexibility, but the relationship is mediated by the embracing and implementation of SCM practices within SMEs.

Several recommendations can be put forward, based on the conclusions drawn from the study. First, it has to be acknowledged that the relationship between customer satisfaction, SCM practices and the three input factors as examined in this study is of fundamental importance to SMEs. In light of this, it is critical that SMEs be educated regarding the importance of these factors. Second, SMEs should consider forming strategic alliances and outsource suppliers to form part of the production process in order to realise and improve on the organisation's core competences such as product quality as well as flexibility. Finally, it can be recommended that a strategic training programme aimed at assisting SMEs in correlating the supply chain objectives with the business strategies outlined in the study should be implemented. This should also assist in mitigating any forthcoming supply chain challenges. For example, if challenges such as lack of skills among SMEs, high cost of information technology and financial constraints are addressed, SMEs will have greater agility in handling other surprising challenges such as greater demands from order givers, competition in domestic markets, increased global competition, and organisational transformation, higher customer expectations of services and products and increased environmental concerns. SMEs may continue to experience challenges in implementing SCM practices if they are not managed by properly qualified individuals. 


\section{REFERENCES}

Agus, A., Hassan, Z. (2011) Enhancing production performance and customer performance through Total Quality Management (TQM): strategies for competitive advantage, Procedia Social and Behavioral Sciences, 24, 1650-1662.

Ahmed, P.K., Hardaker, G., Carpenter, M. (1996) Integrated flexibility - key to competition in a turbulent environment, Long Range Planning, 29(4), 562-571.

Ahola, T., Laitinen, E., Kujala, J., Wikstrom, K. (2008) Purchasing strategies and value creation in industrial turnkey, International Journal of Project Management, 26, 87-94.

Autry, C.W. (2005) Formalization of reverse logistics programs: A strategy for managing liberalized returns, Industrial Marketing Management, 34, 749-757.

Ballou, R.H. (2004) Business Logistics/Supply Chain Management: planning, organising, and controlling the supply chain, $4^{\text {th }}$ ed, Upper Saddle River, NJ: Prentice Hall.

Bhutta, M.K.S., Rana, A.I., Asad, U. (2008) Owner characteristics and health of SMEs in Pakistan, Journal of Small Business and Enterprise Development, 15(1), 130-149.

Bon, A.T., Mustafa, E.M.A. (2013) Impact of Total Quality Management on innovation in service organisations: literature review and new conceptual framework, Procedia Engineering, 53, 516-529.

Bowersox, D.J., Closs, D.J., Cooper, M.B. (2002) Supply chain logistics management, Boston, Mass: McGraw-Hill.

Caridi, M., Cavalieri, S. (2004) Multi-agent systems in production planning and control: An overview, Production Planning and Control, 15(2), 106-118.

Chen, W.H. (1999). The manufacturing strategy and competitive priority of SMEs in Taiwan: A case survey, Asia Pacific Journal of Management, 16, 331-349.

Chow, C.K.W. (2014) Customer satisfaction and service quality in the Chinese airline, Journal of Air Transport Management, 35, 102-107.

Choy, K.L., Chow, H.K.H., Tan, K.H., Chan, C.K., Mok, E.C.M., Wang, Q. (2008) Leveraging the supply chain flexibility of third party logistics: Hybrid knowledgebased system approach, Expert Systems with Application, 35, 1998-2016.

Coyle, J.J., Bardi, E.J., Langley C.J. (2003) The Management of Business Logistics: A supply chain perspective, 7th ed. Canada: Thomson Learning.

Creswell, J.W. (2013). Research Design: Qualitative, Quantitative, and Mixed Methods Approaches. London: Sage Publication.

Denis, D.J. (2011) Multiple linear regression using SPSS, Retrieved August 20, 2012 from: http://psychweb.psy.umt.edu//denis/datadecision/front/stat_II_2011/psyx_521_multiple_ regresson_part_Il.pdf.

Dolgui, A., Prodhon, C. (2007), Supply planning under uncertainties in MRP environments: A state of the art, Annual Reviews in Control, 31, 269-279.

Duclos, L.K., Vokurka, R.J. Lummus,R.R. (2003) A conceptual model of supply chain flexibility, Industrial Management and Data System, 103(6), 446-456.

Ellegaard, C. (2006) Small company purchasing: A research agenda, Journal of Purchasing and Supply Management, 12, 272-283.

Field, A. (2009) Discovering statistics using SPSS (and sex and drugs and rock ' $n$ ' roll), Los Angeles, CA: Sage.

Fouché, C.B. (2005). Qualitative research designs. In De Vos, A.S., Strydom, H., Fouché, C.B. and Delport, C.S.L. Research at Grass Roots for the Social Services and Human Services Professions. 3rd ed. Pretoria: Van Schaik Publishers: 267-273.

Genchev, S.E. (2009) Reverse logistics program design: A company study, Business Horizons, 52, 139-148.

Gong, Z. (2008) An economic evaluation model of supply chain flexibility, European Journal of Operational Research, 184, 745-758. 
Gosling, J., Purvis, L., Naim, M.M. (2009) Supply chain flexibility as a determinant of supplier selection, International of Journal of Production Economics, 1, 1-11.

Herrmann, A., Huber, F., Braunstein, C. (2000) Market-driven product and service design: Bridging the gap between customer needs, quality management, and customer satisfaction, International Journal of Production Economics, 66, 77-96.

Hong, J. (2007) Transport and the location of foreign logistics firms: The Chinese experience, Transportation Research Part A, 41, 597-609.

Horn, S., Pesonen, H. (2014) Evaluating the Climate SWOT as a tool for defining climate strategies for business. Journal of Cleaner Production, 64, 562-571.

Horvath, P.A., Autry, C.W., Wilcox, W.E. (2005) Liquidity implications of reverse logistics for retailers: A Markov chain approach, Journal of Retailing, 18(3), 191-203.

Hugo, W.M.J., Babenhorst-weiss, J.A., Van rooyen, D.C. (2002) Purchasing and Supply Management, 4th ed. Pretoria: Van Schaik Publishers.

Kim, D., Cavusgil, S.T., Cavusgil, E. (2013) Does IT alignment between supply chain partners enhance customer value creation? An empirical investigation, Industrial Marketing Management, 42, 880-889.

Lai, K.H., Ngai, E.W.T., Cheng, T.C.E. (2002) Measures for evaluating supply chain performance in transport logistics, Transportation Research Part E, 38, 439-456.

Langford, J.W. (2007) Logistics principle and applications. $2^{\text {nd }}$ ed, NY: McGraw-Hill.

Lindahl, P., Robert, K.H., Ny, H., Broman, G. (2014) Strategic sustainability considerations in materials management, Journal of Cleaner Production, 64, 98-103.

Ling-yee, L., Ogunmokun, G.O. (2008) An empirical study of manufacturing flexibility of exporting firms in China: How do strategic and organisational contexts matter? Industrial Marketing Management, 37, 738-751.

Malhotra, N.K. (2010). Marketing research: an applied orientation. $6^{\text {th }}$ ed. Eaglewood cliffs: Prentice-hall.

March, S.T., Hevner, A.R. (2007) Integrated decision support systems: A data warehousing perspective, Decision Support System, 43, 1031-1043.

Matzler, K., Hinterhuber, H.H. (1998) How to make product development projects more successful by integrating Kano's model of customer satisfaction into quality function deployment, Technovation, 18(1), 25-38.

Mentzer, J.T., Flint, D.J., Hult, T.M. (2001) Logistics Service Quality as a SegmentCustomised process, Journal of Marketing, 65, 82-104.

Millen, R, Sohal, A., Moss, S. (1999) Quality management in the logistics function: An empirical study, International Journal of Quality and Reliability Management, 16(2), 166-180.

Molz R. (1998) Steps to Strategic Management: A Guide for Entrepreneurs, NY: Word Ware Publishing Inc.

Mostert, J.W., Oosthuizen, A.G., Smith, P.C., Van der vyver, T.C. (2007) Micro-economics: A Southern African Perspective, Cape Town: Juta.

Mukherjee, D., Gaur, A.S., Datta, A. (2013) Creating value through offshore outsourcing: an integrative framework, Journal of International Management, 19, 377-389.

Mula, J., Poler, R., Garcia-sabater, J.P., Lario, F.C. (2006) Models for production planning under uncertainty: A review, International Journal of Production Economics, 103, 271-285.

Muradzikwa, S., Smith, L., De Villiers, P. (2004) Economics, NY: Oxford University Press.

Narasimhan, R., Talluri, S. (2004) Exploring flexibility and execution competencies of manufacturing firms, of Journal of Operations Management, 22, 91-106.

Nath, P., Nachiappan, S., Ramanathan, R. (2010) The impact of marketing capability, operations capability and diversification strategy on performance: a resource-based view, Industrial Marketing Management, 39, 317-329. 
Park, Y.T. (2006) An empirical investigation of the effects of data warehousing on decision performance, Information and Management, 43, 51-61.

Paulraj, A., Chen, I.J., Flynn, J. (2006) Levels of strategic purchasing: Impact on supply integration and performance, Journal of Purchasing and Supply Management, 12, 107-122.

Prakash, G. (2011) Service quality in supply chain: empirical evidence from Indian automotive industry, Supply Chain Management: An International Journal, 16(5), 362-378.

Ramond, L., Croom, S. (2008) The impact of evolutionary and developmental metaphors on Purchasing and Supply Management: A critique, Journal of Purchasing and Supply Management, 14, 192-204.

Rosenbusch, N., Brinckmann, J., Bausch, A. (2011) Is innovation always beneficial? A menta-analysis of the relationship between innovation and performance in SMEs, Journal of Business Venturing, 26, 441-457.

Sanchez, A.M., Perez, M.P. (2005) Supply chain flexibility and firm performance: A conceptual model and empirical study in the automotive industry, International Journal of Operations and Production Management, 25(7), 681-700.

Saura, I.G., Frances, D.S., Contri, G.B., Blasco, M.F. (2008) Logistics service quality: A new way to loyalty, Industrial Management and Data Systems, 108(5), 650-668.

Schwarz, C. (2014) Toward an understanding of the nature and conceptualisation of outsourcing success, Information and Management, 51, 152-164.

Sharifl, H., Ismail, H.S., Qiu, J., Tavani, S.N. (2013) Supply chain strategy and its impacts on product and market growth strategies: a case study of SMEs, International Journal of Production Economics, 145, 397-408.

Shin, J., Lee, H. (2013), Low-risk opportunity recognition from mature technologies for SMEs, Journal of Engineering and Technology Management, 30, 402-418.

Skintzi, G., Ioannou,G. and Prastacos, G. (2008). Investigating warehousing policies. International Journal of Product Economics, 112, 955-970.

Sohal, A.S., Netto, B.D., Fitzpatrick, P., Noori, H. (2001). The roles and responsibilities of production/operations managers in SMEs: evidence from Canada, Technovation, 21, 437-448.

Song, D.P., Dong, J.X., Xu, J. (2014) Integrated inventory management and supplier base reduction in a supply chain with multiple uncertainties, European Journal of Operational Research, 232, 522-536.

Subramanian, N., Gunasekaran, A., Yu, J., Cheng, J., NING, K. (2014) Customer satisfaction and competitiveness in the Chinese E-retailing structural equation modelling (SEM) approach to identify the role of quality factors, Expert Systems with Applications, 41, 6-80.

Sui, W., Lin, T., Fang, W., Lui, Z.C. (2006) An institutional analysis of the new product development process of small and medium enterprises (SMEs) in China, Hong Kong and Taiwan, Industrial Marketing Management, 35, 323-335.

Sun, K.A., Kim, D.Y. (2013) Does customer satisfaction increase firm performance? An application of American Customer Satisfaction Index (ACSI), International Journal of Hospitality Management, 35, 68-77.

Tachizawa, E.M., Gimenez, C. (2010) Supply flexibility strategies in Spanish firms: Results from a survey, International Journal of Production Economics, 124, 214-224.

Tassabehji, R., Moorhouse, A. (2008) The changing role of procurement: Developing professional effectiveness, Journal of Purchasing and Supply Management, 14, 5568.

Taylor, G.D. (2008) Logistics engineering handbook, Boca Raton, NY: CRC Press. 
Terpstra, M., Verbeeten. FHM. (2014) Customer satisfaction: Cost driver or value driver? Empirical evidence from the financial services industry. European Management Journal, 32, 3, 499-508.

Todorut, A.V. (2012) Sustainable development of organisations through total quality management, Procedia -Social and Behavioral Sciences, 62, 927-931.

Van der vorst, J.G.A.J., Beulens, A.J.M., Van beek, P. (2005) Innovations in logistics and ICT in food supply chain networks, In Jongen, W.M.F., Meulenberg, M.T.G., ed. Innovation in Agric-Food System, Wageningen: Wageningen Academic Publishers, pp: 245-292.

Venter, P. (2006) Analysing the internal environment. In Louw, L., Venter, P., ed, Strategic Management: winning in the Southern African workplace, Cape Town: Oxford, pp: 148-174.

Voortman, C. (2004) Global logistics Management, Lansdowne, Cape Town: Juta.

Waller, D.L. (2003) Operational management: $A$ supply chain approach. $2^{\text {nd }}$ ed. Bedford Row, London: Thomson.

Watson, H.J., Goodhue, D.L., Wixom, B.H. (2001) The benefits of data warehousing: Why some organisations realise exceptional payoffs, Information and Management, 39, 491-502.

Wixom, B.H., Watson, H.J. (2001) An empirical investigation of the factors affecting data warehousing success, MIS Quarterly, 25(1), 17-41.

Wong, C.W.Y., Karia, N. (2010) Explaining the competitive advantage of logistics service providers: a resource-based view approach, International Journal of Production Economics, 128, 51-67.

Wong, C.W.Y., Lai, K.H., Ngai, E.W.T. (2009) The role of supplier operational adaptation on the performance of IT-enabled transport logistics under environmental uncertainty, International Journal of Production Economics, 122, 47-55.

Zhang, Q., Vonderembse, M.A., Su Lim, J. (2003) Manufacturing flexibility: Defining and analysing relationships among competence, capability, and customer satisfaction, Journal of Operational Management, 21, 173-191. 